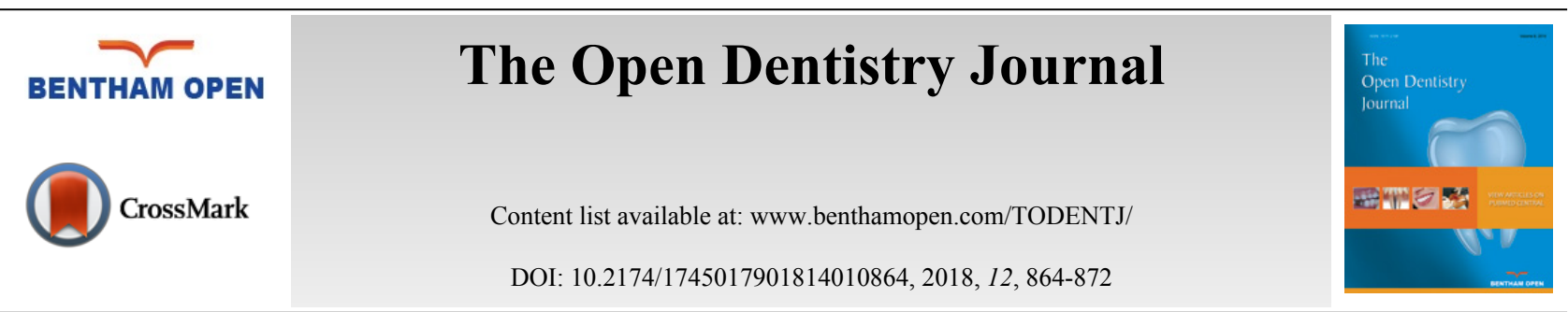

REVIEW ARTICLE

\title{
Separation of Nickel-Titanium Rotary and Reciprocating Instruments: A Mini-Review of Clinical Studies
}

\author{
Marcelo Santos Coelho ${ }^{1, *}$, Marcos de Azevêdo Rios ${ }^{2}$ and Carlos Eduardo da Silveira Bueno ${ }^{1}$ \\ ${ }^{I}$ Department of Endodontics, São Leopoldo Mandic Dental Research Center, Campinas, SP, Brazil \\ ${ }^{2}$ Department of Endodontics, State University of Feira de Santana, Feira de Santana, Brazil
}

Received: April 14, 2018

Revised: July 26, 2018

Accepted: September 23, 2018

\begin{abstract}
:
Objective:

This review aimed to evaluate clinical studies that assessed separated NiTi rotary and reciprocating instruments.

\section{Design and Methods:}

This review assessed clinical studies involving treatments performed by undergraduate students, graduate students, and endodontic specialists. This review evaluated studies using rotary instruments, reciprocating instruments, and hybrid techniques. The number of uses of the different NiTi rotary and reciprocating systems was also assessed.
\end{abstract}

\section{Results:}

The incidence of separation for rotary instruments ranged from $0 \%$ to $23 \%$. Rotary instruments were used from 1 to 50 times depending on the instrument and tooth type. The lowest rate of incidence separation for rotary instruments was obtained by undergraduate students, using a hybrid technique. The separation incidence for reciprocating instruments ranged from $0 \%$ to $1.71 \%$. Reciprocating instruments were mostly single-used; one study reported their use up to 3 times. Separation rate in reciprocating instruments was similar in single-use or in multiple uses $0.2 \%$.

\section{Conclusions:}

Separation of instruments has dropped recently and seems to be a minor problem in current Endodontics. Multiple uses of NiTi rotary instruments are a possibility without significantly increasing the risk of instrument separation. Single and multiple uses of NiTi reciprocating instruments are also associated with low incidence of separation. Attempting to remove separated instruments should be carefully evaluated.

Keywords: Nickel-titanium, Root canal treatment, Rotary, Reciprocating, Separation, Dentinal defects.

\section{INTRODUCTION}

The introduction of the Nickel-Titanium (NiTi) alloy in endodontics has rendered the manufacturing of more flexible and resistant instruments [1]. Since the initial hand files, the use of this alloy has permitted centralized and reliable preparation [2]. Currently, NiTi rotary instruments are part of the daily armamentarium of the endodontist and general practitioner with a great variety of instruments presenting different cross-sections, tapers, and new variations of the original alloy [3].

Up to the present moment, due to the anatomic complexity, none of the systems has been able to a complete cleaning of the root canal system [4]. However, NiTi rotary and reciprocating instrum of debris, while maintaining the

\footnotetext{
* Address correspondence to this author at the Department of Endodontics, São Leopoldo Mandic Dental Research Center, Rua José Rocha Junqueira, 13, Campinas - SP, Brazil; Tel: +55 1998111 6525, Email: coelho_marcelo@yahoo.com.br
} 
centralized preparation [5,6]. The possibility of dentinal defects creation has been suggested [7]; however, recent studies have demonstrated that dentinal defects are unlikely to be related with root canal instrumentation [8]. Despite the advantages of NiTi instruments, the risk of instrument separation is still a concern for the practitioner [9], mainly because this event might occur without previous sign of instrument distortion [10].

The incidence of serious incidents involving separated instruments can be considered very low [11]. Panitvisai et al., [9], have also shown that when an instrument remains inside the canal, it is not necessarily related to a poor outcome. However, when the instrument prevents the optimal sealing of the apical third, especially in necrotic teeth, the outcome may be compromised [12]. One important factor to be considered is the risk involved in the attempt of the removal of the separated instrument.

Several studies have shown the behavior of instruments in laboratory studies $[13,14]$ and after clinical use [15]. The different kinds of forces that lead to instrument separation, cyclic fatigue, or torsional fatigue have been described in different instruments [16]. Pre-flaring and glide path creation has also been recommended in some systems [17, 18].

Recent clinical studies have described the rate of instrument separation in different NiTi instruments operating in rotary or reciprocating kinematics. These studies have presented controversial results according to the operator's experience, the number of use of the instruments, and the kinematics involved $[8,19,20]$.

Thus, the aim of this study is to review the studies that evaluated the rate of separated NiTi rotary and reciprocating instruments in clinical situations.

\section{CAUSES}

When a file rotates inside the root canal, it goes through different forces. In a curve canal, the greater risk is related to the cyclic fatigue; in a narrow canal, the torsional or sheer stress is the greater source of concern.

Irregularities in the instruments might lead to separation due to cyclic fatigue. In the curve portion of the root canal, cracks presented in the instrument suffer compression forces when in the inner part of the curvature, and tension forces in the external portion. The more an instrument rotates inside the canal, the greater number of tension and compression acting in these cracks, therefore increasing the risk of separation [21]. Under a clinical point of view, it is notable that this type of fracture might occur without signs of distortion. Rotary instruments presenting larger sizes require attention when used in curved canals to avoid separation due to cyclic fatigue [16].

When the tip of an instrument binds in a canal and the remnant portion of the instruments rotates, it creates a torsion fatigue. By increasing the cross-section area and the number of threads, the torsional stiffness increases. This results in lessening the risk of separation. The clinician should be aware that in addition to the instrument design applied, the electropolishing used in NiTi instruments diminishes the number of irregularities present and helps decrease the risk of instrument separation $[22,23]$.

According to Sattapan et al., [24], torsion fatigue occurred in $55.7 \%$ of the separated instruments assessed after clinical use. On the other hand, Wei et al., [25], found that, after observing 100 NiTi separated instruments during clinical use, $91 \%$ of the separations were due to cyclic fatigue, torsion fatigue occurred in $3 \%$ of the cases and, the combination of both in $6 \%$ of the cases.

Therefore, the selection of a proper instrument is paramount to avoid separation. It seems reasonable that flexible instruments are recommended for curved canals and stiffer instruments to avoid torsional fracture.

\section{ROTARY KINEMATICS}

The engine-driven instrumentation of root canal system is an aim of clinical endodontics since the beginning of XX Century. These tools aim to decrease the preparation time and simplification of root canal instrumentation. Nonetheless, in the early era of engine-driven instruments there was a high risk of instrument separation when compared to hand instruments. Instrument separation of NiTi Rotary instruments might occur due to torsion, cyclic fatigue or a combination of both forces.

The clinical approach to discard Rotary instruments, aiming to avoid the separation is the number of uses. However, the number of times an instrument can be used with minimum risk of separation is still unclear: different studies show controversial data.

A study has compared cyclic fatigue resistance of ProFile instruments used in maxillary and mandibular molars with 
a control group of unused instruments [15]. That study showed no difference between the groups, therefore concluding that ProFile instruments can be safely used in up to 4 molars. Cheung et al., [26], have clinically evaluated the separation rate of ProTaper S1 instruments. The instruments were used up to 4 times in molars, 20 times in premolars, and 50 times in incisors and canines; the 325 instruments collected showed a separation rate of $23 \%$. Wolcott et al., [20], found a separation rate of ProTaper instruments of $2.4 \%$, and no difference was found in the incidence of separation for the first 4 uses of the instrument. An evaluation of Lightspeed instruments showed a separation rate of $3.7 \%$; the remarkable result of that study is that 5 out of 6 instruments were used up to 11 times [27].

Recent studies, however, have presented lower rates of instrument separation (Fig. 1). Ehrahdt et al., [28], have evaluated the Mtwo NiTi rotary instruments. After a glide path creation, $1.98 \%$ of the files separated; the number of uses in this study was up to 5 times unless the instrument presented signs of distortion. Wu et al., [29], found 1.1\% of separated ProTaper instruments even with multiple uses: 3 times for molars, 10 times for premolars, and 30 times for anterior teeth. In that study, the instruments were only discarded after single-use in complex cases. Shen et al., [30, 31], have presented $0.3 \%$ for ProFile instrument files used up to 3 times, and $0.05 \%$ for ProFile Vortex files used by graduate students in a single use regimen. Coelho et al., [32], have presented no instrument separation in an undergraduate endodontic clinic. The NiTi rotary Vortex instruments were used in 3 root canal treatments if no sign of distortion was present [32]. A recent clinical study has shown a separation rate of $0.83 \%$ for the Twisted File Adaptive after the use in 3 molars; no instrument separation occurred in the 2 first uses [33].

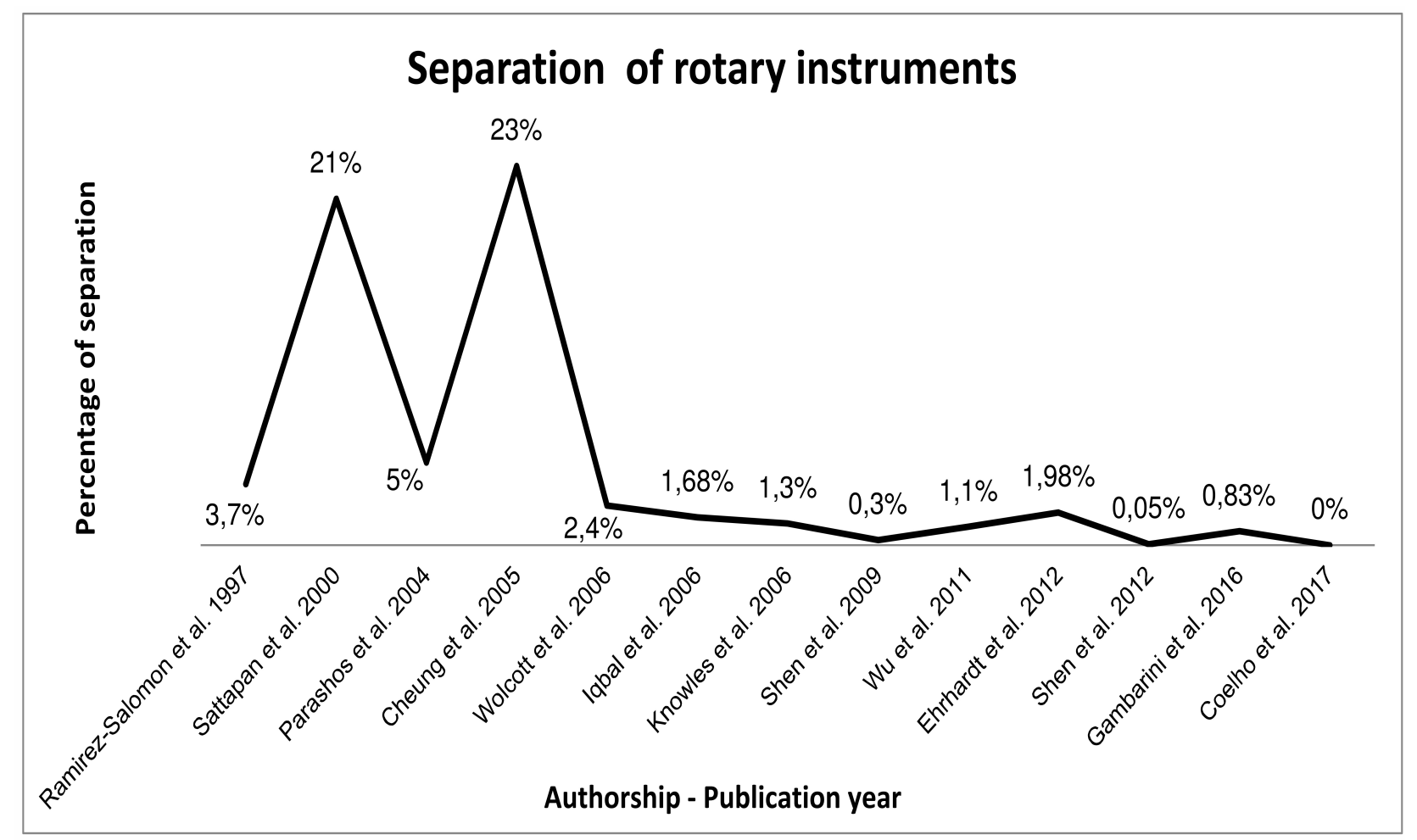

Fig. (1). Clinical studies assessing separation of NiTi rotary instruments.

The aforementioned findings are in agreement with a previous study. By evaluating 7,159 instruments discarded by 14 endodontists from 4 different countries, Parashos et al., [34], evaluated the factors that might lead to instrument separation. It seems that the number of uses is not a primordial factor that causes instruments to separate. Indeed, multiple uses of instruments are not necessarily related to increase the risk of separation as far as NiTi rotary instruments are properly assessed for signs of distortion or discarded when submitted to complex anatomies. The clinician should be aware that while an instrument can separate without previous unwinding, this deformation suggests that the instrument should be discarded immediately [35].

\section{RECIPROCATING KINEMATICS}

A single-file reciprocating system for NiTi instruments has been suggested, claiming to diminish the necessary steps 
for root canal preparation. Besides, the single use of these instruments would decrease the risk of cross-contamination and instrument separation [36]. Indeed, laboratorial studies demonstrated that the shift of the kinematics, presenting a cutting angle larger than the relief angle, increases the resistance to the cyclic fatigue when the reciprocating asymmetrical movement is applied [21]. The critical areas of stress move progressively to new locations during the periodical change of the angle, thus distributing effectively the areas of stress to different points of the instrument decreasing the damage and increasing the life span of the instrument.

Clinical studies have demonstrated that these instruments present a low rate of separation when a single use approach is applied (Fig. 2). Cunha et al., assessed 711 cases treated with the WaveOne system; after the creation of a glide path, the instruments were used to instrument 2,215 canals in posterior teeth. The separation rate of this prospective study was of $0.42 \%$ on a tooth level and $0.13 \%$ considering the number of canals [19]. Shen et al., [37], have presented $0.5 \%$ of 438 WaveOne instruments collected after clinical use; Coelho et al., have shown no separation of WaveOne instruments used in an undergraduate endodontic clinic [32]. The WaveOne system is manufactured with an M-Wire NiTi alloy which presents 390\% more cyclic fatigue resistance then regular NiTi [38]. A recent study assessed the negotiability of MB2 canals by using the Reciproc R25 instrument, a reciprocating single-file system; within 341 successfully instrumented canals, the separation rate was $1.7 \%$ [39]. A clinical evaluation of 3,780 root canal preparations done in primary and retreatment cases with the Reciproc system led to similar results: $0.4 \%$ of separation per tooth and $0.2 \%$ per canal [40]. Despite the similar alloy and kinematics used in the WaveOne System, Reciproc does not require a glide path. The specific cross-section of Reciproc follows the natural curvature of the root canal, sparing the glide path step.

\section{Separation of reciprocating instruments}

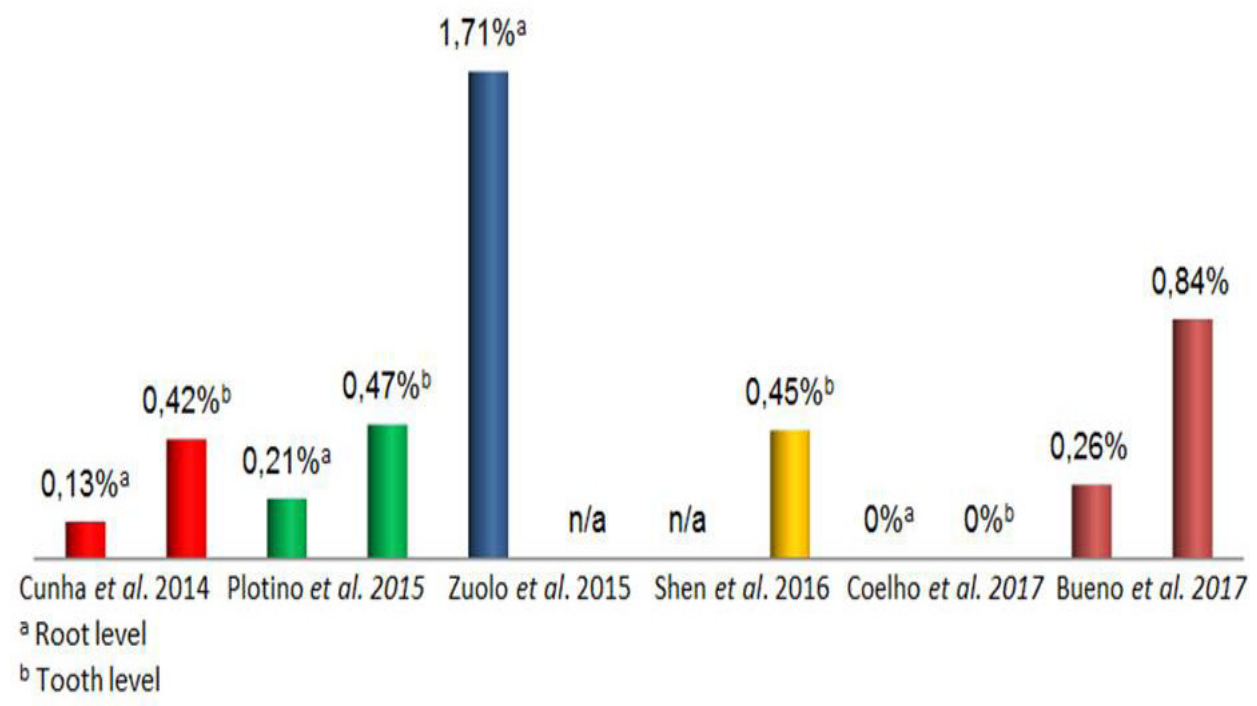

Fig. (2). Reciprocating Instruments - percentage of separation in clinical studies.

* Only MB2 canals evaluated in this study.

A recent study has shown that both WaveOne and Reciproc instruments presented low rates $-0.2 \%$ of separation even after 3 uses [41]. The single-use recommendation of these instruments in based on concerns in regards to crosscontamination and risk of separation. It is our understanding that whether or not these instruments should be discarded after single use, the same procedure should be applied to hand and rotary instruments. As the kinematics increase the time required to fracture [13], it seems reasonable that, under appropriate case selection and observation after using, the instruments might be used multiple times. 


\section{OPERATOR EXPERIENCE}

Knowles et al., [42], assessed 3,543 canals treated in a 24-month interval by undergraduate students. The separation rate found was $1.3 \%$ of Lightspeed instruments. Hanni et al., [43], in 87 cases among 40 undergraduate students, showed no file separation; the number of uses in this study is not specified. It is important to emphasize that those undergraduate students had an intense preclinical training, having opportunity to separate instruments without clinical consequences. Shen et al., have presented $0.3 \%$ of ProFile Vortex instrumented, separated in a 4-year interval. A following study showed 1 ProFile Vortex instrument separated in 2,203 instruments (0.05\%); in both studies, the cases were completed by undergraduate students. A recent study also has shown no instrument separation for NiTi Rotary and reciprocating instruments [32]. The cases were performed by $3^{\text {rd }}$ and $4^{\text {th }}$ year undergraduate students. That study followed the American Association of Endodontists selection case guidelines, meaning that the 715 cases treated were primary treatment of teeth, presenting no complex anatomies.

Iqbal et al., [10], evaluated 10,237 canals treated in 4,685 cases by graduate students in a 4-year interval. Different NiTi rotary systems were used (Light Speed, ProTaper, ProFile, GT Taper, and K3); the overall rate of instrument separation was $1.68 \%$ on a tooth level and $0.67 \%$ on a root level. Graduate students were assessed by Shen et al., [37], when the WaveOne reciprocating instruments were used. That study showed that single-use of WaveOne instruments separated in 1 out of 85 cases $(1.17 \%)$ and 1 out of 90 cases $(1.11 \%)$ in one of the specialist clinics assessed. Three endodontic specialists' clinics had no separation for the WaveOne system.

Some other studies assessed the separation rate of instruments after clinical use by endodontic specialists. Satappan et al., [44], evaluated the Quantec NiTi rotary instruments collected during a 6-month interval. The separation rate registered was $21 \%$. However, the authors could neither assure that the full sequence of instruments was used nor the number of uses for each instrument. An important aspect of this study is that the instruments were discarded when the cutting efficiency was clinically observed or when signs of distortion were noted. Other studies that evaluated separation rate of rotary NiTi instruments presented better outcomes such as $1.98 \%$ for the Mtwo system after a glide path creation [28], 3.7\% for Light Speed Instruments [27], 2.4\% for ProTaper instruments [29], and 0.83\% for Twisted Files Adaptive [33].

Likewise, three recent studies presented similar results with reciprocating instruments used by Endodontic specialists [19, 37, 40]. The rate of instrument separation was low for both WaveOne and Reciproc instruments evaluated in these recent studies. While in the past pre flaring or glide path were recommend to avoid instrument separation [17], the Reciproc system does not require such steps. Yet, the risk of separation of this system is, at least, as low as others. This might be considered an important advantage for clinicians, reducing preparation time and decreasing the risk of separation.

The incidence of separation among undergraduate and graduate students seems to be similar to the ones done by endodontic specialists. This might be due to the case selection adopted (usually primary treatments of uncomplicated cases), the assistance by specialist faculty during the procedures, and the intense preclinical training. General dentists can take advantage of NiTi rotary and reciprocating instruments.

A comparison among different studies is not an easy task; different files were used with different cross-sections and number of uses. For rotary instruments, a reasonable reuse of instruments seems to not increase the risk of instrument separation $^{34}$. Some studies do not state the number of uses of the instruments. However, it is remarkable that the incidence of instrument separation has dropped in the last few years. A better treatment of the instrument's surface, the novel thermomechanical treatment, kinematics, and case selection might have contributed in obtaining these results.

\section{INSTRUMENT REMOVAL}

Nevertheless, the clinician should decide the better approach when faced with the situation of an instrument separation. Removal of the separated portion, by-passing the instrument, or just not attempting to remove it should be considered. It is worthwhile to notice that instrument separation is not directly associated to failure. A follow-up of 8 patients with irretrievable instruments has shown that after 5 years, $100 \%$ of these patients presented functional teeth [45]. Only $12.5 \%$ of these patients presented with radiographic characteristics of no healing. That is likely to happen if the fragment prevents a proper cleaning of the apical third in a necrotic case [9].

A classical instrument removal is the Masserann kit, which has been shown to remove up to 55\% of the instruments. The major drawback of this system is that the instrument is removed at the expense of dentin destruction [46]. Nevares et al., [47], have demonstrated in a clinical situation that the combination of D.O.M and ultrasonic tips are efficient for 
the removal of separated instruments. In that study, $85.3 \%$ of the visible fragments were removed or by-passed when visible, and $47.7 \%$ removed or by-passed when not visible. Similarly, a previous study has shown that $83.33 \%$ of the instruments could be by-passed [27]. Usually, by-passing the instrument is the first step in instrument removal procedures. If this step is achieved, the outcome is not different from removed instruments, so the separated instrument management can be considered successful [48].

Gentle Wave is a new approach for removal of separated instruments [49]. It has promoted in vitro the removal of $42 \%$ to $91 \%$ of the fragments, depending on the curvature and location. However, this information is still limited to a laboratory study and with fragments of $2.5 \mathrm{~mm}$, which is not the most frequent in a clinical situation. Therefore this $i n$ vitro study might have overestimated the actual benefits of applying this device in vivo for separated instruments removal.

It is our understanding that an attempt of instrument removal after the curvature is too risky to overtake the benefits. The data of previous studies is still controversial in regards of the benefits of instrument removal. Meanwhile several manufactures advertise their products which might be assessed with caution. A higher benefit would be achieved by following-up with the patient clinically and radiographically, especially in cases of vital pulp. Periapical microsurgery should be the best solution for these situations in most cases.

\section{CONCLUSION}

Separation rate of NiTi rotary instruments has dropped recently and seems to be a minor problem in current Endodontics. The number of uses of an instrument with minimum risk of separation is still unknown. General dentists can benefit from the use of NiTi instruments as soon as the case is properly selected. Attempting to remove separated instruments should be carefully evaluated, as they can be often by-passed or be kept inside the root canal without compromising the outcomes.

\section{CONSENT FOR PUBLICATION}

Not applicable.

\section{CONFLICT OF INTEREST}

The authors declare no conflict of interest, financial or otherwise.

\section{ACKNOWLEDGEMENTS}

Declared none.

\section{REFERENCES}

[1] Walia HM, Brantley WA, Gerstein H. An initial investigation of the bending and torsional properties of Nitinol root canal files. J Endod 1988; 14(7): $346-51$.

[http://dx.doi.org/10.1016/S0099-2399(88)80196-1] [PMID: 3251996]

[2] Pettiette MT, Delano EO, Trope M. Evaluation of success rate of endodontic treatment performed by students with stainless-steel K-files and nickel-titanium hand files. J Endod 2001; 27(2): 124-7.

[http://dx.doi.org/10.1097/00004770-200102000-00017] [PMID: 11491636]

[3] Hieawy A, Haapasalo M, Zhou H, Wang ZJ, Shen Y. Phase transformation behavior and resistance to bending and cyclic fatigue of ProTaper gold and ProTaper universal instruments. J Endod 2015; 41(7): 1134-8.

[http://dx.doi.org/10.1016/j.joen.2015.02.030] [PMID: 25841955]

[4] Paqué F, Zehnder M, De-Deus G. Microtomography-based comparison of reciprocating single-file F2 ProTaper technique versus rotary full sequence. J Endod 2011; 37(10): 1394-7.

[http://dx.doi.org/10.1016/j.joen.2011.06.031] [PMID: 21924189]

[5] Ferraz CC, Gomes NV, Gomes BP, Zaia AA, Teixeira FB, Souza-Filho FJ. Apical extrusion of debris and irrigants using two hand and three engine-driven instrumentation techniques. Int Endod J 2001; 34(5): 354-8. [http://dx.doi.org/10.1046/j.1365-2591.2001.00394.x] [PMID: 11482718]

[6] Peters OA. Current challenges and concepts in the preparation of root canal systems: A review. J Endod 2004; 30(8): 559-67. [http://dx.doi.org/10.1097/01.DON.0000129039.59003.9D] [PMID: 15273636]

[7] Jamleh A, Komabayashi T, Ebihara A, et al. Root surface strain during canal shaping and its influence on apical microcrack development: A preliminary investigation. Int Endod J 2015; 48(12): 1103-11. [http://dx.doi.org/10.1111/iej.12406] [PMID: 25377258] 
[8] Coelho MS, Card SJ, Tawil PZ. Light-emitting diode assessment of dentinal defects after root canal preparation with profile, TRUShape, and WaveOne gold systems. J Endod 2016; 42(9): 1393-6. [http://dx.doi.org/10.1016/j.joen.2016.06.003] [PMID: 27421973]

[9] Panitvisai P, Parunnit P, Sathorn C, Messer HH. Impact of a retained instrument on treatment outcome: A systematic review and metaanalysis. J Endod 2010; 36(5): 775-80. [http://dx.doi.org/10.1016/j.joen.2009.12.029] [PMID: 20416418]

[10] Iqbal MK, Kohli MR, Kim JS. A retrospective clinical study of incidence of root canal instrument separation in an endodontics graduate program: A PennEndo database study. J Endod 2006; 32(11): 1048-52. [http://dx.doi.org/10.1016/j.joen.2006.03.001] [PMID: 17055904]

[11] Nayak RN, Hiremath S, Shaikh S, Nayak AR. Dysesthesia with pain due to a broken endodontic instrument lodged in the mandibular canal-A simple deroofing technique for its retrieval: Case report. Oral Surg Oral Med Oral Pathol Oral Radiol Endod 2011; 111(2): e48-51. [http://dx.doi.org/10.1016/j.tripleo.2010.10.002] [PMID: 21084201]

[12] Fu M, Zhang Z, Hou B. Removal of broken files from root canals by using ultrasonic techniques combined with dental microscope: A retrospective analysis of treatment outcome. J Endod 2011; 37(5): 619-22. [http://dx.doi.org/10.1016/j.joen.2011.02.016] [PMID: 21496659]

[13] Gavini G, Caldeira CL, Akisue E, Candeiro GT, Kawakami DA. Resistance to flexural fatigue of Reciproc R25 files under continuous rotation and reciprocating movement. J Endod 2012; 38(5): 684-7. [http://dx.doi.org/10.1016/j.joen.2011.12.033] [PMID: 22515903]

[14] Kim HC, Kwak SW, Cheung GS, Ko DH, Chung SM, Lee W. Cyclic fatigue and torsional resistance of two new nickel-titanium instruments used in reciprocation motion: Reciproc versus WaveOne. J Endod 2012; 38(4): 541-4. [http://dx.doi.org/10.1016/j.joen.2011.11.014] [PMID: 22414846]

[15] Yared GM, Bou Dagher FE, Machtou P. Cyclic fatigue of ProFile rotary instruments after clinical use. Int Endod J 2000; 33(3): 204-7. [http://dx.doi.org/10.1046/j.1365-2591.1999.00296.x] [PMID: 11307436]

[16] Baek SH, Lee CJ, Versluis A, Kim BM, Lee W, Kim HC. Comparison of torsional stiffness of nickel-titanium rotary files with different geometric characteristics. J Endod 2011; 37(9): 1283-6. [http://dx.doi.org/10.1016/j.joen.2011.05.032] [PMID: 21846549]

[17] Berutti E, Negro AR, Lendini M, Pasqualini D. Influence of manual preflaring and torque on the failure rate of ProTaper rotary instruments. J Endod 2004; 30(4): 228-30.

[http://dx.doi.org/10.1097/00004770-200404000-00011] [PMID: 15085052]

[18] Berutti E, Paolino DS, Chiandussi G, et al. Root canal anatomy preservation of WaveOne reciprocating files with or without glide path. J Endod 2012; 38(1): 101-4. [PMID: 22152630]

[19] Cunha RS, Junaid A, Ensinas P, Nudera W, Bueno CE. Assessment of the separation incidence of reciprocating WaveOne files: A prospective clinical study. J Endod 2014; 40(7): 922-4. [http://dx.doi.org/10.1016/j.joen.2014.03.016] [PMID: 24935536]

[20] Wolcott S, Wolcott J, Ishley D, et al. Separation incidence of protaper rotary instruments: A large cohort clinical evaluation. J Endod 2006; 32(12): 1139-41.

[http://dx.doi.org/10.1016/j.joen.2006.05.015] [PMID: 17174668]

[21] De-Deus G, Moreira EJ, Lopes HP, Elias CN. Extended cyclic fatigue life of F2 ProTaper instruments used in reciprocating movement. Int Endod J 2010; 43(12): 1063-8. [http://dx.doi.org/10.1111/j.1365-2591.2010.01756.x] [PMID: 21080616]

[22] Anderson ME, Price JW, Parashos P. Fracture resistance of electropolished rotary nickel-titanium endodontic instruments. J Endod 2007; 33(10): 1212-6.

[http://dx.doi.org/10.1016/j.joen.2007.07.007] [PMID: 17889692]

[23] Tripi TR, Bonaccorso A, Condorelli GG. Cyclic fatigue of different nickel-titanium endodontic rotary instruments. Oral Surg Oral Med Oral Pathol Oral Radiol Endod 2006; 102(4): e106-14. [http://dx.doi.org/10.1016/j.tripleo.2005.12.012] [PMID: 16997084]

[24] Sattapan B, Palamara JEA, Messer HH. Torque during canal instrumentation using rotary nickel-titanium files. J Endod 2000; 26(3): 156-60.

[25] Wei X, Ling J, Jiang J, Huang X, Liu L. Modes of failure of ProTaper nickel-titanium rotary instruments after clinical use. J Endod 2007; 33(3): 276-9.

[http://dx.doi.org/10.1016/j.joen.2006.10.012] [PMID: 17320713]

[26] Cheung GS, Peng B, Bian Z, Shen Y, Darvell BW. Defects in ProTaper S1 instruments after clinical use: Fractographic examination. Int Endod J 2005; 38(11): 802-9.

[http://dx.doi.org/10.1111/j.1365-2591.2005.01020.x] [PMID: 16218972]

[27] Ramirez-Salomon M, Soler-Bientz R, de la Garza-González R, Palacios-Garza CM. Incidence of Lightspeed separation and the potential for bypassing. J Endod 1997; 23(9): 586-7. [http://dx.doi.org/10.1016/S0099-2399(06)81128-3] [PMID: 9587288] 
[28] Ehrhardt IC, Zuolo ML, Cunha RS, et al. Assessment of the separation incidence of mtwo files used with preflaring: Prospective clinical study. J Endod 2012; 38(8): 1078-81. [http://dx.doi.org/10.1016/j.joen.2012.05.001] [PMID: 22794209]

[29] Wu J, Lei G, Yan M, Yu Y, Yu J, Zhang G. Instrument separation analysis of multi-used ProTaper Universal rotary system during root canal therapy. J Endod 2011; 37(6): 758-63. [http://dx.doi.org/10.1016/j.joen.2011.02.021] [PMID: 21787484]

[30] Shen Y, Coil JM, Haapasalo M. Defects in nickel-titanium instruments after clinical use. Part 3: A 4-year retrospective study from an undergraduate clinic. J Endod 2009; 35(2): 193-6. [http://dx.doi.org/10.1016/j.joen.2008.11.003] [PMID: 19166771]

[31] Shen Y, Coil JM, Zhou HM, Tam E, Zheng YF, Haapasalo M. ProFile Vortex instruments after clinical use: A metallurgical properties study. J Endod 2012; 38(12): 1613-7. [http://dx.doi.org/10.1016/j.joen.2012.09.018] [PMID: 23146647]

[32] Coelho MS, Card SJ, Tawil PZ. Safety assessment of two hybrid instrumentation techniques in a dental student endodontic clinic: A Retrospective Study. J Dent Educ 2017; 81(3): 333-9. [PMID: 28250040]

[33] Gambarini G, Piasecki L, Di Nardo D, et al. Incidence of deformation and fracture of twisted file adaptive instruments after repeated clinical use. J Oral Maxillofac Res 2016; 7(4): e5. [http://dx.doi.org/10.5037/jomr.2016.7405] [PMID: 28154749]

[34] Parashos P, Gordon I, Messer HH. Factors influencing defects of rotary nickel-titanium endodontic instruments after clinical use. J Endod 2004; 30(10): 722-5. [http://dx.doi.org/10.1097/01.DON.0000129963.42882.C9] [PMID: 15448468]

[35] Chakka NV, Ratnakar P, Das S, Bagchi A, Sudhir S, Anumula L. Do NiTi instruments show defects before separation? Defects caused by torsional fatigue in hand and rotary nickel-titanium (NiTi) instruments which lead to failure during clinical use. J Contemp Dent Pract 2012; 13(6): 867-72. [PMID: 23404017]

[36] Yared G. Canal preparation using only one Ni-Ti rotary instrument: Preliminary observations. Int Endod J 2008; 41(4): 339-44. [http://dx.doi.org/10.1111/j.1365-2591.2007.01351.x] [PMID: 18081803]

[37] Shen Y, Coil JM, Mo AJ, et al. WaveOne rotary instruments after clinical use. J Endod 2016; 42(2): 186-9. [http://dx.doi.org/10.1016/j.joen.2015.10.008] [PMID: 26654140]

[38] Johnson E, Lloyd A, Kuttler S, Namerow K. Comparison between a novel nickel-titanium alloy and 508 nitinol on the cyclic fatigue life of ProFile 25/.04 rotary instruments. J Endod 2008; 34(11): 1406-9. [http://dx.doi.org/10.1016/j.joen.2008.07.029] [PMID: 18928858]

[39] Zuolo ML, Carvalho MC, De-Deus G. Negotiability of second mesiobuccal canals in maxillary molars using a reciprocating system. J Endod 2015; 41(11): 1913-7.

[http://dx.doi.org/10.1016/j.joen.2015.08.004] [PMID: 26443438]

[40] Plotino G, Grande NM, Porciani PF. Deformation and fracture incidence of Reciproc instruments: A clinical evaluation. Int Endod J 2015; 48(2): 199-205.

[http://dx.doi.org/10.1111/iej.12302] [PMID: 24754602]

[41] Bueno CSP, Oliveira DP, Pelegrine RA, Fontana CE, Rocha DGP, Bueno CEDS. Fracture incidence of WaveOne and reciproc files during root canal preparation of up to 3 posterior teeth: A Prospective clinical study. J Endod 2017; 43(5): 705-8. [http://dx.doi.org/10.1016/j.joen.2016.12.024] [PMID: 28343932]

[42] Knowles KI, Hammond NB, Biggs SG, Ibarrola JL. Incidence of instrument separation using Lightspeed rotary instruments. J Endod 2006; 32(1): 14-6.

[http://dx.doi.org/10.1016/j.joen.2005.10.008] [PMID: 16410061]

[43] Hänni S, Schönenberger K, Peters OA, Barbakow F. Teaching an engine-driven preparation technique to undergraduates: Initial observations. Int Endod J 2003; 36(7): 476-82. [http://dx.doi.org/10.1046/j.1365-2591.2003.00677.x] [PMID: 12823703]

[44] Sattapan B, Nervo GJ, Palamara JE, Messer HH. Defects in rotary nickel-titanium files after clinical use. J Endod 2000; 26(3): 161-5. [http://dx.doi.org/10.1097/00004770-200003000-00008] [PMID: 11199711]

[45] Hansen JR, Beeson TJ, Ibarrola JL. Case series: Tooth retention 5 years after irretrievable separation of Lightspeed LSX instruments. J Endod 2013; 39(11): 1467-70. [http://dx.doi.org/10.1016/j.joen.2013.06.031] [PMID: 24139276]

[46] Hülsmann M, Schinkel I. Influence of several factors on the success or failure of removal of fractured instruments from the root canal. Endod Dent Traumatol 1999; 15(6): 252-8. [http://dx.doi.org/10.1111/j.1600-9657.1999.tb00783.x] [PMID: 10825835]

[47] Nevares G, Cunha RS, Zuolo ML, Bueno CE. Success rates for removing or bypassing fractured instruments: A prospective clinical study. J Endod 2012; 38(4): 442-4. 
[http://dx.doi.org/10.1016/j.joen.2011.12.009] [PMID: 22414826]

[48] Madarati AA, Hunter MJ, Dummer PM. Management of intracanal separated instruments. J Endod 2013; $39(5): 569-81$. [http://dx.doi.org/10.1016/j.joen.2012.12.033] [PMID: 23611371]

[49] Wohlgemuth P, Cuocolo D, Vandrangi P, Sigurdsson A. Effectiveness of the Gentlewave system in removing separated instruments. J Endod 2015; 41(11): 1895-8

[http://dx.doi.org/10.1016/j.joen.2015.08.015] [PMID: 26409807]

\section{(C) 2018 Coelho et al.}

This is an open access article distributed under the terms of the Creative Commons Attribution 4.0 International Public License (CC-BY 4.0), a copy of which is available at: (https:/creativecommons.org/licenses/by/4.0/legalcode). This license permits unrestricted use, distribution, and reproduction in any medium, provided the original author and source are credited. 